\title{
HAEMODYNAMIC CHANGES DUE TO CLAMPING OF THE ABDOMINAL AORTA
}

\author{
R. Meloche, T. Pottecher, ${ }^{\circ}$ J. Audet, O. Dufresne, and C. LePage
}

Serious problems arise frequently during anaesthesia for major vascular surgery associated with clamping of the aorta. Haemodynamic changes at the moment of recirculation are readily observed and have been the subject of numerous publications. ${ }^{1-4}$ The hypotension, at times severe, that follows the unclamping of the aorta is not without danger for these arteriosclerotic and hypertensive patients. It is obvious that hypotension, even of short duration, can reduce cerebral, coronary or renal perfusion and jeopardize an otherwise successful operation.

While the period of unclamping has been thoroughly examined, the events associated with clamping have not received much attention except for Perry's animal experiments, which showed decrease in cardiac output. ${ }^{5}$ The proximal occlusion of the aorta during operation for thoracic aneurysm can induce alarming increases in blood pressure and experienced anaesthetists will look for signs of left ventricular failure. The use of nitroprusside is often mandatory to relieve the acute afterload while the surgeon prepares a temporary bypass. It is not uncommon to see pulsus alternans, indicating ventricular failure probably due to discrepancy in regional perfusion of an already diseased myocardium.

The clamping of the distal aorta also induces haemodynamic changes, the most obvious response again being the increase in systolic pressure due to an afterload which could be of clinical significance for these patients. With that in mind we decided to investigate the haemodynamic changes due to cross-clamping of the abdominal aorta. We also attempted to evaluate renal function during and following operation and to correlate changes, if any, to haemodynamic alterations. The latter will be the subject of a future publication.

\section{Material and Methodology}

Eighteen patients requiring surgery of the abdominal aorta were included in this study. None presented clinical evidence of cardiac insufficiency or dysrythmia before operation. They were distributed at random in two groups involving nine Leriches and nine aneurysms of the infrarenal aorta. Anthropometric data and type of surgery are summarized in Table $I$.

After premedication with diazepam $5 \mathrm{mg}$ intramuscularly, induction of anaesthesia was carried out with thiopentone $5 \mathrm{mg} / \mathrm{kg}$, and pancuronium $0.15 \mathrm{mg} / \mathrm{kg}$ for tracheal intubation and muscular relaxation. Maintenance was achieved with

From the Department of Anaesthesia, Hôpital Notre-Dame, Montréal.

'Resident in anaesthesia (Université Louis-Pasteur, Strasbourg, France).

Reprint requests to: Dr $\mathrm{R}$. Meloche c/o Department of Anaesthesia, Hôpital Notre-Dame, C.P. 1560, Montréal, P.Q., H2L 4 K8. 
TABLE I

ANThropometric Data and TYPE OF SURGERY

\begin{tabular}{|c|c|c|c|c|c|c|}
\hline No. & Diagnosis* & Age & Sex & $\begin{array}{l}\text { Height } \\
\text { (M) }\end{array}$ & $\begin{array}{c}\text { Weight } \\
(\mathrm{K} g)\end{array}$ & $\begin{array}{l}\mathrm{BSA} \\
\left(\mathrm{M}^{2}\right)\end{array}$ \\
\hline 1 & $\mathrm{~L}$ & 70 & $\mathrm{M}$ & 1.66 & 66 & 1.73 \\
\hline 2 & A & 78 & $\mathbf{M}$ & 1.71 & 64 & 1.75 \\
\hline 3 & $\mathrm{~L}$ & 44 & $\mathrm{~F}$ & 1.60 & 40 & 1.37 \\
\hline 4 & $\bar{L}$ & 57 & $\mathrm{M}$ & 1.73 & 63 & 1.75 \\
\hline 5 & A & 69 & $\mathbf{M}$ & 1.75 & 58 & 1.70 \\
\hline 6 & L & 65 & $\mathrm{~F}$ & 1.60 & 64 & 1.67 \\
\hline 7 & A & 68 & $\mathrm{M}$ & 1.68 & 70 & 1.79 \\
\hline 8 & A & 65 & $\mathrm{M}$ & 1.68 & 47 & 1.52 \\
\hline 9 & A & 70 & $\mathrm{M}$ & 1.60 & 52 & 1.52 \\
\hline 10 & A & 68 & $\mathrm{M}$ & 1.63 & 56 & 1.59 \\
\hline 11 & $\mathrm{~L}$ & 53 & $\mathrm{~F}$ & 1.63 & 55 & 1.58 \\
\hline 12 & $\mathrm{~L}$ & 50 & $\mathrm{M}$ & 1.70 & 73 & 1.84 \\
\hline 13 & $\mathrm{~L}$ & 52 & $\mathbf{F}$ & 1.58 & 67 & 1.68 \\
\hline 14 & $\bar{A}$ & 61 & $\mathrm{M}$ & 1.68 & 83 & 1.94 \\
\hline 15 & $\mathrm{~A}$ & 56 & $\mathrm{M}$ & 1.78 & 68 & 1.85 \\
\hline 16 & A & 76 & $\mathrm{M}$ & 1.65 & 73 & 1.79 \\
\hline 17 & L & 70 & $\mathrm{~F}$ & 1.53 & 46 & 1.40 \\
\hline 18 & L & 52 & $\mathrm{M}$ & 1.68 & 86 & 1.96 \\
\hline
\end{tabular}

$* \mathrm{~L}=$ Leriche: age $57(\mathrm{SD} \pm 9.2) . \mathrm{P}<0.02$.

$\mathrm{A}=$ Aneurysm: age $68(\mathrm{SD} \pm 6.7) . \mathrm{P}<0.02$.

nitrous-oxide oxygen and fentanyl according to analgesic requirements. Droperidol $0.1 \mathrm{mg} / \mathrm{kg}$ was also given before the surgical incision.

The left radial artery was cannulated under general anaesthesia after testing for adequacy of cubital artery compensatory function. A catheter was placed in the right atrium through the internal jugular vein; its position was ascertained by threading to the right ventricle and withdrawal into the atrium, the characteristic pressure signal being displayed on an oscilloscope.

All patients were placed on controlled ventilation with a tidal volume of $10 \mathrm{ml} / \mathrm{kg}$ at a frequency of $12 / \mathrm{min}$. A control arterial blood gas analysis was performed routinely at the start of the procedure. Necessary adjustments to maintain $\mathrm{Pa}_{2}$ and $\mathrm{Pa}_{\mathrm{O}_{2}}$ within normal limits were rapidly applied. Fluid intake was adjusted to $20 \mathrm{ml} / \mathrm{kg} / \mathrm{hr}$ before aortic clamping, half the volume consisting of 5 per cent glucose in water and the other half 5 per cent glucose with 0.45 per cent $\mathrm{NaCl}$. A rather liberal fluid intake was administered prior to clamping in order to ensure that hypovolaemia would not explain the haemodynamic changes. Furthermore, in patients with over twelve hours of water restriction, it is important to prevent an augmentation in serum osmolality with subsequent release of antidiuretic hormone. Following occlusion of the aorta, fluid intake was reduced to $6 \mathrm{ml} / \mathrm{kg} / \mathrm{hr}$. Blood loss was replaced as accurately as possible.

Haemodynamic data (E.K.G., arterial and right atrial pressure curves and dilution curve) were inscribed on a polygraph recorder (Mingograph EMT 81 Elema-Schonander). Pressures were continuously recorded from the amplified signals of Statham P23dB transducers. Mechanical and electrical calibrations were obtained and checked regularly during the investigation.

Cardiac output was determined by injection of indocyanine green dye into the right atrium and detection of the resulting dye dilution curve in the arterial blood by a Waters $\mathrm{D}-400$ densitometer. The surface under the curve was calculated by 
computer from ordinates taken at 1-second intervals. The recirculation was eliminated by extrapolating the exponential portion of the curve using a least square method. A special program was written which permitted us to obtain results as well as statistics from the computer thus eliminating human bias (varian 73). Derived variables were obtained as follows:

$$
\begin{aligned}
\text { SVR } & =\frac{\overline{\mathrm{AP}}-\overline{\mathrm{RAP}}}{\mathrm{C} . \mathrm{O} .} \times 79.92 \text { dynes.sec. } \mathrm{cm}^{-5} \\
\mathrm{SV} & =\frac{\mathrm{C} . \mathrm{O} .}{\mathrm{HR}}=\mathrm{ml} \\
\mathrm{C} . \mathrm{I} . & =\mathrm{C} . \mathrm{O} \cdot / \mathrm{m}^{2} \\
\text { LVSWI } & =\overline{\mathrm{AP}}(\mathrm{SI}) 1.36 \times 10^{-2}=\mathrm{g} \cdot{\mathrm{m} . \mathrm{m}^{-2}}^{-2} \\
\mathrm{PTI} & =\mathrm{HR} \times \text { syst. AP } \times 10^{-3}
\end{aligned}
$$

Where SVR is the systemic vascular resistance expressed in dynes.sec.cm-5; SV is the stroke volume in ml; LVSWI the left ventricular stroke-work index in grammetre and PTI, the pressure time index.

In both groups the study was conducted as follows: pressure signals and standard Lead II of the EKG were recorded continuously: three control cardiac output determinations were obtained just before the clamping of the aorta and every two minutes for the first ten minutes after aortic occlusion. The same data were also collected five minutes before unclamping; the three last cardiac output curves being obtained at the end of the operation after stabilization of vital signs. Statistical analysis of the data applied two-tailed T-tests for comparison within groups and unpaired T-tests for comparison between groups. Unless otherwise mentioned, only statistically significant variations will be presented and discussed.

\section{Results}

The results are tabulated using the mean of the readings in all patients with the standard error in brackets. Significant variations within the group $(\mathrm{p}<0.05)$ as related to the control are followed by an asterisk and the statistically valid variations between the two groups $(\mathrm{p}<0.05)$ are indicated by a cross.

Tables II to VIII show the variations of the measured parameters in the 18 patients. In the first ten minutes after clamping it can be seen that the heart rate, right atrial pressure, systolic work of the left ventricle, and the pressure time index do not differ from the control values at zero time (Figures 1-2). On the other hand, immediately after two minutes of aortic occlusion there is a significant increase in systolic arterial pressure and in systemic vascular resistance and a significant decrease in cardiac index (Tables IV, V, VI), at the expense of the stroke volume (Table VII). The maximum changes take place after eight minutes of clamping, at which time the systolic pressure has increased by 13 per cent, the vascular resistance by 37 per cent and the cardiac output has decreased by 18 per cent. After 50 minutes of aortic occlusion, while the systolic and right atrial pressures 
TABLE II

Changes in Right Atrial Pressure and Heart Rate Due to Aortic Occlusion (MEANS $\pm \mathrm{SE}$ ) $\mathrm{N}=18$

\begin{tabular}{ccc}
\hline \hline Time & $\overline{\text { RAP }}$ Torr & HR \\
\hline 0 & $6.6(0.8)$ & $81(3.7)$ \\
$2^{\prime}$ & $6.2(0.9)$ & $82(3.5)$ \\
$4^{\prime}$ & $6.2(0.8)$ & $81(3.7)$ \\
$6^{\prime}$ & $6.2(0.8)$ & $80(3.9)$ \\
$8^{\prime}$ & $6.2(0.8)$ & $82(4.0)$ \\
$10^{\prime}$ & $6.1(0.8)$ & $82(4.4)$ \\
\hline
\end{tabular}

Patients were stıdied before $(\mathrm{T}=0)$ and after clamping $\left(\mathrm{T}=2^{\prime} \ldots\right)$.

TABLE III

Changes in Lefr Ventriculak Systolic Work INDEX BEFORE $(T=0)$ AND AFTER AORTIC Occlusion (Means $\pm \mathrm{SE}$ ) $\mathrm{N}=18$

\begin{tabular}{cc}
\hline Time & LVSWI (g.m.m $\left.{ }^{-9}\right)$ \\
\hline 0 & $50.1(3.0)$ \\
$2^{\prime}$ & $49.0(3.7)$ \\
$4^{\prime}$ & $48.6(3.3)$ \\
$6^{\prime}$ & $47.9(3.8)$ \\
$8^{\prime}$ & $44.7(3.2)^{*}$ \\
$10^{\prime}$ & $45.0(3.8)$ \\
\hline$* \mathrm{P}<0.02$ &
\end{tabular}

Patients were studied before $(\mathbf{T}=0)$ and after aortic occlusion $\left(T=2^{\prime} \ldots\right)$.

TABLE IV

Systolic Arterial Pressure Changes Due to Aortic Occlusion (Means $\pm \mathrm{SE}$ ) $\mathrm{N}=18$

\begin{tabular}{cc}
\hline \hline Time & AP Torr \\
\hline 0 & $155(5.7)$ \\
$2^{\prime}$ & $171.1(5.5)^{*}$ \\
$4^{\prime}$ & $178.6(5.6)^{*}$ \\
$6^{\prime}$ & $173.4(6.3)^{*}$ \\
$8^{\prime}$ & $175.6(6.7)^{*}$ \\
$10^{\prime}$ & $174.6(6.4)^{*}$ \\
\hline
\end{tabular}

Patients were studied before $(T=0)$ and every $2^{\prime}$ after the clamping of infrarenal aorta $\left(\mathrm{T}=2^{\prime}\right.$
$* \mathrm{P}$

and heart rate are not different from the controls, the cardiac index has dropped by 29 per cent and the resistance is augmented by 50 per cent (Table VIII).

Table IX compares the systolic arterial pressure changes between Leriche $(\mathrm{N}=9)$ and aneurysm $(\mathrm{N}=9)$. There are no significant variations between groups except after four minutes of clamping. There is a tendency for the systolic pressures to be higher in the aneurysm group, though this does not reach a significant level. 
TABLE $V$

Changes in Systemic Vascular Resistance Due to Aortic Occlusion (Means $\pm \mathrm{SE}$ ) $\mathrm{N}=18$

\begin{tabular}{cc}
\hline \hline Time & $\mathrm{R}\left(\right.$ dynes.sec.cm $\left.{ }^{-5}\right)$ \\
\hline 0 & $1989(201)$ \\
$2^{\prime}$ & $2392(232)^{*}$ \\
$4^{\prime}$ & $2542(223)^{*}$ \\
$6^{\prime}$ & $2500(224)^{*}$ \\
$8^{\prime}$ & $2732(266)^{*}$ \\
$10^{\prime}$ & $2663(253)^{*}$ \\
\hline
\end{tabular}

Patients were studied before $(T=0)$ and after aortic occlusion $\left(T=2^{\prime} \ldots\right)$.

${ }^{*} \mathrm{P}<0.01$

TABLE VI

Changes in Cardiac Index Induced by Clamping the Infrarenal Aorta (Means $\pm \mathrm{SE}$ ) $\mathrm{N}=18$

\begin{tabular}{cc}
\hline \hline Time & C.I. $\left(1 / \mathrm{min} / \mathrm{m}^{2}\right)$ \\
\hline 0 & $2.78(0.21)$ \\
$2^{\prime}$ & $2.54(0.20)^{*}$ \\
$4^{\prime}$ & $2.41(0.18) \dagger$ \\
$6^{\prime}$ & $2.40(0.18) \dagger$ \\
$8^{\prime}$ & $2.26(0.17) \dagger$ \\
$10^{\prime}$ & $2.27(0.17) \dagger$ \\
\hline
\end{tabular}

$* \mathrm{P}<0.05, \dagger \mathrm{P}<0.01$.

Patients were studied before $(T=0)$ and after aortic occlusion $\left(T=2^{\prime} \ldots\right)$.

TABLE VII

Changes in Stroke Index Due to Aortic Occlusion (MEANS $\pm \mathrm{SE}$ ) $\mathrm{N}=18$

\begin{tabular}{cc}
\hline \hline Time & S.I. $\left.(\mathrm{m}] / \mathrm{min} / \mathrm{m}^{2}\right)$ \\
\hline 0 & $35.9(2.3)$ control \\
$2^{\prime}$ & $31.5(2.4)^{*}$ \\
$4^{\prime}$ & $30.8(2.4)^{*}$ \\
$6^{\prime}$ & $30.8(2.4)^{*}$ \\
$8^{\prime}$ & $28.3(2.2)^{*}$ \\
$10^{\prime}$ & $28.8(2.4)^{*}$ \\
\hline${ }^{*} \mathrm{P}<0.01$. & \\
Patients were studied before $(\mathrm{T}=0)$ and \\
after aortic occlusion $\left(\mathrm{T}=2^{\prime} \ldots\right)$.
\end{tabular}

The variations in cardiac and stroke indices are shown in Table X. The decrease following aortic occlusion is not significantly different in the Leriche group as compared to the aneurysm group. The same is noted in Table XI, which indicates that the increase in systemic vascular resistance, though slightly more in the aneurysm group, does not reach statistical significance.

The overall picture of haemodynamic changes before, during and after aortic 
$N=18$

Heart rate $( \pm S E$ )

- Mean right atrial pressure $( \pm S E)$

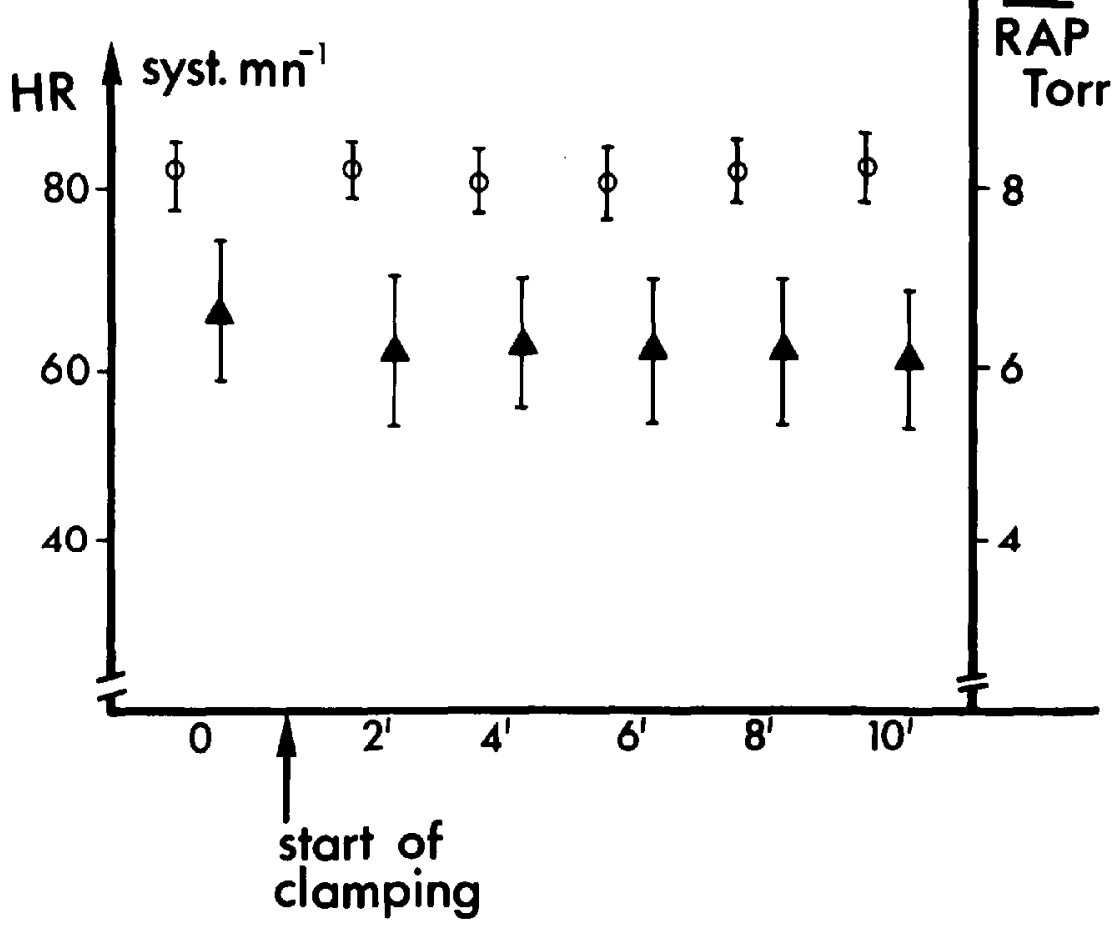

Figune 1. Neither the heart rate nor the right atrial pressure are modified by clamping the infrarenal aorta.

TABLE VIII

Aortic Clamping: Haemodynamic Modifications

\begin{tabular}{rccccccc}
\hline \hline Time & $\begin{array}{c}\text { HR } \\
\text { syst.min }\end{array}$ & $\begin{array}{c}\text { RAP } \\
\text { Torr }\end{array}$ & $\begin{array}{c}\text { LVSW } \\
\text { gm.m }\end{array}$ & $\begin{array}{c}\text { PTI } \\
\text { HR SAP } \times 10^{-3}\end{array}$ & $\begin{array}{c}\text { SAP } \\
\text { Torr }\end{array}$ & $\begin{array}{c}\text { C.I. } \\
\text { 1.min } \text { m. }^{-2}\end{array}$ & $\begin{array}{c}\text { SVR } \\
\text { dynes.sec.cm }\end{array}$ \\
\hline 0 & 82 & 7 & 50.1 & 12.6 & 155 & 2.78 & 1989 \\
$2^{\prime}$ & 81 & 6 & 49.0 & 13.4 & $171^{*}$ & $2.54^{*}$ & $2392^{*}$ \\
$4^{\prime}$ & 80 & 6 & 48.6 & 13.7 & $\mathbf{1 7 8}^{*}$ & $2.41^{*}$ & $251^{*}$ \\
$6^{\prime}$ & 82 & 6 & 47.9 & 13.3 & $173^{*}$ & $2.40^{*}$ & $2500^{*}$ \\
$8^{\prime}$ & 82 & 6 & 44.7 & 13.8 & $175^{*}$ & $2.26^{*}$ & $2732^{*}$ \\
$10^{\prime}$ & 82 & 6 & 45.0 & 13.2 & $174^{*}$ & $2.27^{*}$ & $262^{*}$ \\
$50^{\prime}$ & 81 & 6 & 35.7 & 13.0 & 161 & $1.95^{*}$ & $2996^{*}$ \\
End & 82 & 6 & 44.1 & 12.8 & 156 & 2.57 & 2142 \\
\hline
\end{tabular}

Patients were studied before and after clamping of aorta. 


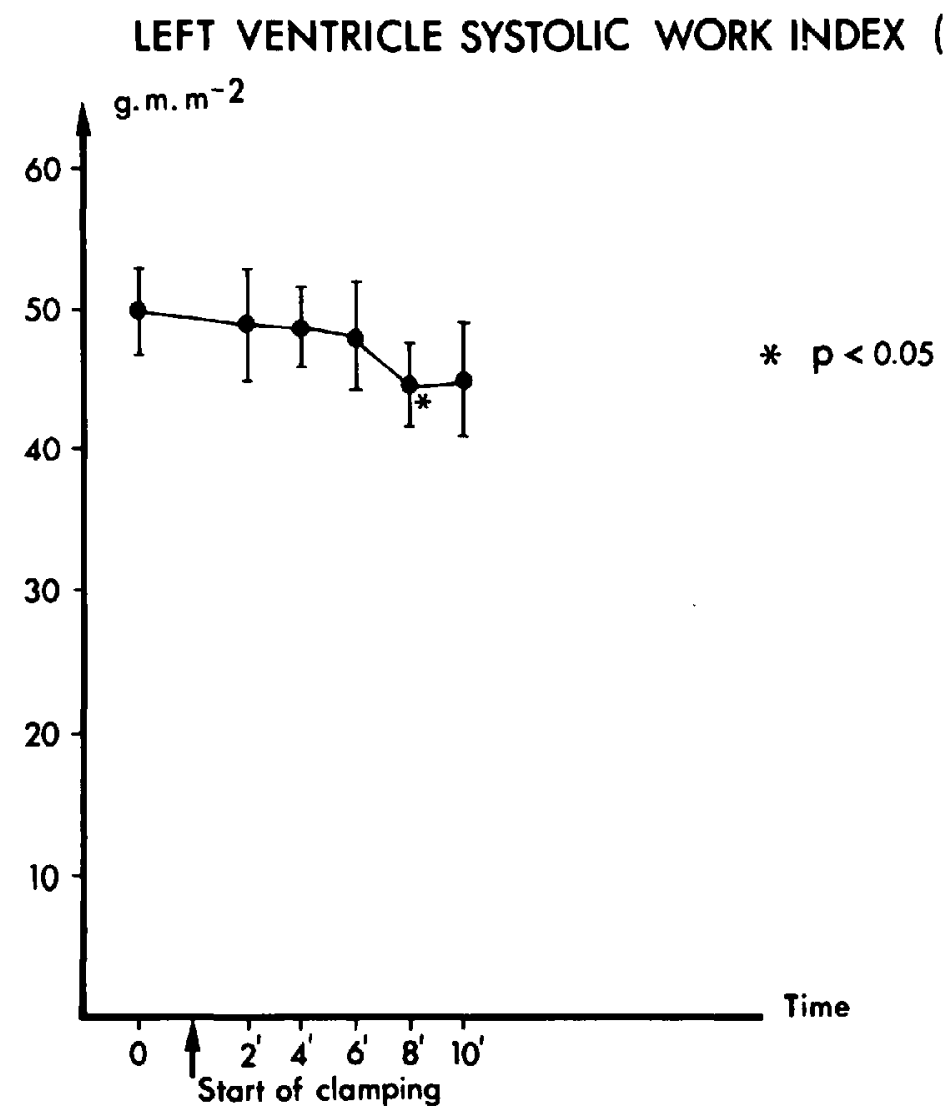

Figure 2. The only significant change in left ventricular systolic work is noted at the eighth minute after clamping the aorta. This absence of response to a 30 per cent increase in vascular resistance explains the reduction of cardiac output.

occlusion is given in Table XII. It shows that apart from changes due to clamping already mentioned, at the end of surgery and once the vital signs have been stabilised, the cardiac output, vascular resistance and systolic pressure are not significantly different from control values.

\section{Discussion}

It should be emphasized that these patients were free from cardiac diseases, that anaesthesia was conducted without undue myocardial depressant doses that $\mathrm{Pa}_{\mathrm{CO}_{2}}$ was maintained at normal levels and fluids administered liberally (20 $\mathrm{ml} / \mathrm{kg} / \mathrm{hr}$ before clamping). Meaningful information can be drawn from these results. Under balanced anaesthesia with droperidol-fentanyl-pancuronium, just before aortic cross-clamping, right atrial and arterial pressures as well as heart rate were normal. Nevertheless, the systemic vascular resistance was elevated and the cardiac and stroke indices were at the lower limits of normality. The clamping of the aorta did induce alarming haemodynamic changes (Figures $3,4,5$ ). The sudden increase in aortic impedance was followed by a 20 per cent reduction in 
TABLE IX

Systolic Arterial Pressure Changes due to Clamping of Aorta. Comparisons of Patients WITH LERICHE SYNDROME $(N=9)$ AND Aneurysm $(\mathrm{N}=9)$. (MEANS $\pm \mathrm{SE}$ )

\begin{tabular}{cccc}
\hline Time & $\begin{array}{c}\text { Leriche } \\
\text { AP Torr }\end{array}$ & & $\begin{array}{c}\text { Aneurysm } \\
\text { AP Torr }\end{array}$ \\
\hline 0 & $148.6(5.2)$ & NS & $160.2(9.5)$ \\
$2^{\prime}$ & $160.5(4.9)^{*}$ & NS & $181.7(8.8)^{*}$ \\
$\mathbf{4}^{\prime}$ & $\mathbf{1 6 7 . 5 ( 5 . 7 ) ^ { * }}$ & + & $189.8(8.3)^{*}$ \\
$\mathbf{6}^{\prime}$ & $\mathbf{1 6 6 . 5 ( 7 . 3 ) ^ { * }}$ & NS & $180.2(9.9)^{*}$ \\
$\mathbf{8}^{\prime}$ & $\mathbf{1 6 4 . 8 ( 6 . 4 ) ^ { * }}$ & NS & $186.3(10)^{*}$ \\
$10^{\prime}$ & $\mathbf{1 6 6 . 7 ( 7 . 1 ) ^ { * }}$ & NS & $182.2(10)^{*}$ \\
\hline
\end{tabular}

$* P<0.01$ within each group.

$+\mathrm{P}<0.05$ between the two series.

Patients were studied before $(T=0)$ and every two minutes after aortic occlusion $\left(T=2^{\prime} \ldots\right)$.

TABLE X

Cardiac and Stroke Indices Changes Due to Clamping of Aorta. Comparisons of Patients with Leriche $(\mathrm{N}=9)$ and Patients WITH ANEURYSM $(\mathrm{N}=9)$

\begin{tabular}{cccccc}
\hline \hline & \multicolumn{2}{c}{ Leriche } & & \multicolumn{2}{c}{ Aneurysm } \\
\cline { 2 - 3 } \cline { 5 - 6 } Time & $\begin{array}{c}\text { C.I. } \\
\text { 1/min } / \mathrm{m}^{2}\end{array}$ & $\begin{array}{c}\text { S.I. } \\
\mathrm{ml} / \mathrm{min} / \mathrm{m}^{2}\end{array}$ & & $\begin{array}{c}\text { C.I. } \\
\text { l/min } / \mathrm{m}^{2}\end{array}$ & $\begin{array}{c}\text { S.I. } \\
\mathrm{ml} / \mathrm{min}^{2} / \mathrm{m}^{2}\end{array}$ \\
\hline 0 & 2.77 & 35 & & 2.79 & 36.7 \\
$2^{\prime}$ & 2.49 & $29 \dagger$ & & 2.59 & $33.5 \dagger$ \\
$4^{\prime}$ & 2.49 & $31^{*}$ & & $2.34 \dagger$ & $30.6 \dagger$ \\
$6^{\prime}$ & $2.41^{*}$ & $29 \dagger$ & & $2.39^{*}$ & $32.0^{*}$ \\
$8^{\prime}$ & $2.27 \dagger$ & $27 \dagger$ & & $2.25^{*}$ & $28.5 \dagger$ \\
$10^{\prime}$ & $2.27 \dagger$ & $27 \dagger$ & & $2.26^{*}$ & $28.7 \dagger$ \\
\hline
\end{tabular}

There is no significant difference between the two series $(+)$ while a significant variation is shown within each group ( $\mathrm{P}<0.05, \dagger \mathrm{P}<0.01)$.

Patients were studied before $(T=0)$ and after aortic occlusion $\left(T=2^{\prime} \ldots\right)$.

cardiac output at the expense of the stroke volume. The cardiac performance deteriorated because the derived left ventricular work did not change, though the latter could be questioned because the left ventricular filling pressure was not used in its determination. Adjustment does not appear to occur with time; on the contrary, owing to blood losses, evaporation and oozing, all difficult to appraise, and in spite of adequate replacement, after 50 minutes of aortic clamping the cardiac output is even lower. Five minutes before unclamping, right atrial and arterial pressures being at control values, heart rate at 81 , cardiac index was lower than 2 litres per minute and vascular resistances almost reached 3000 dynes.

It was not possible to document a significant difference in the behaviour of patients with chronic obstruction of blood flow to lower extremities (Leriche) and those with a somewhat more acute disease (aneurysm). Nevertheless, it can be seen that the former have a tendency to show less marked haemodynamic changes. As the patients with aneurysm are older, one can surmise that they had a certain degree of iliac obstruction and that younger subjects with traumatic aneurysm would show a larger increase in resistance following aortic cross-clamping. 
TABLE XI

\begin{tabular}{|c|c|c|}
\hline & Leriche & Aneurysm \\
\hline Time & SVR (dynes.sec.cm ${ }^{-5}$ ) & SVR (dynes.sec..cm- ${ }^{-b}$ ) \\
\hline 0 & $2064(363)$ & $1915(196)$ \\
\hline $2^{\prime}$ & $2364(384)^{*}$ & $2421(286)+$ \\
\hline $4^{\prime}$ & $2349(337)^{*}$ & $2733(296) \dagger$ \\
\hline $6^{\prime}$ & $2430(329) \dagger$ & $2570(322) \dagger$ \\
\hline $8^{\prime}$ & $2497(284) \dagger$ & $2996(464) \dagger$ \\
\hline $10^{\prime}$ & $2564(352) \dagger$ & $2762(382) \dagger$ \\
\hline
\end{tabular}

* $\mathrm{P}<0.05,+\mathrm{P}<0.01$.

Patients were studied before $(\mathrm{T}=0)$ and after aortic occlusion $\left(T=2^{\prime} \ldots\right)$.

TABLE XII

Haemodynamic Changes Before, During and After Clamping OF AORTA $(\mathrm{N}=18)$

\begin{tabular}{lccccc}
\hline & HR & $\begin{array}{c}\text { SAP } \\
\text { Torr }\end{array}$ & $\begin{array}{c}\text { C.I. } \\
\text { l/min/m }\end{array}$ & $\begin{array}{c}\text { SVR } \\
\text { dynes.sec.cm }\end{array}$ & $\begin{array}{c}\text { RAP } \\
\text { Torr }\end{array}$ \\
\hline Control & 82 & 155 & 2.78 & 1989 & 7 \\
& $(3.2)$ & $(5.7)$ & $(0.21)$ & $(201)$ & $(0.8)$ \\
During & 81 & $174^{*}$ & $2.37 *$ & $2565^{*}$ & 6 \\
clamping & $(1.8)$ & $(6.1)$ & $(0.18)$ & $(239)$ & $(0.8)$ \\
End of & 82 & 156 & 2.57 & 2142 & 6 \\
surgery & $(1.9)$ & $(5.4)$ & $(0.17)$ & $(220)$ & $(0.8)$ \\
\hline
\end{tabular}

"P $<0.05$.

It is obvious that an increase in afterload can reduce the cardiac output. Nevertheless, in physiological conditions there are mechanisms which can maintain the stroke volume in spite of this load. First, the Starling mechanism. The increase in afterload leads to an increase in the amount of blood remaining in the ventricle at the end of the systole. This means that the next end diastolic volume will be larger, thence an elongation of the fibre will take place. Following this elongation, the mechanism described by Patterson, Piper and Starling will be put in action and the stroke volume will be maintained. ${ }^{\theta}$

A second mechanism can be called upon to maintain the stroke volume against the larger afterload; it is the positive inotropic effect due to systolic pressure increase. ${ }^{7}$ This reflex was demonstrated by Anrep in 1912, and Starling believed it to be the result of the enhancement of coronary perfusion by the increased aortic pressure. ${ }^{8}$ Nearly half a century later, Sarnoff ${ }^{9}$ demonstrated that the Anrep reflex did not call upon an increase in coronary flow, thus confirming the results of Rosenblueth and Taquini. ${ }^{10,11}$ For these authors the increase in activity of the myocardium induces an enhancement of contractility after a few beats; the ventricular work is augmented and the rate of rise of ventricular pressure is more rapid. This takes place without any change in end-diastolic pressure and thus without the intervention of the Starling mechanism. For Sarnoff this homeometric autoregulation depends on the level of circulating catecholamines. This means that at 


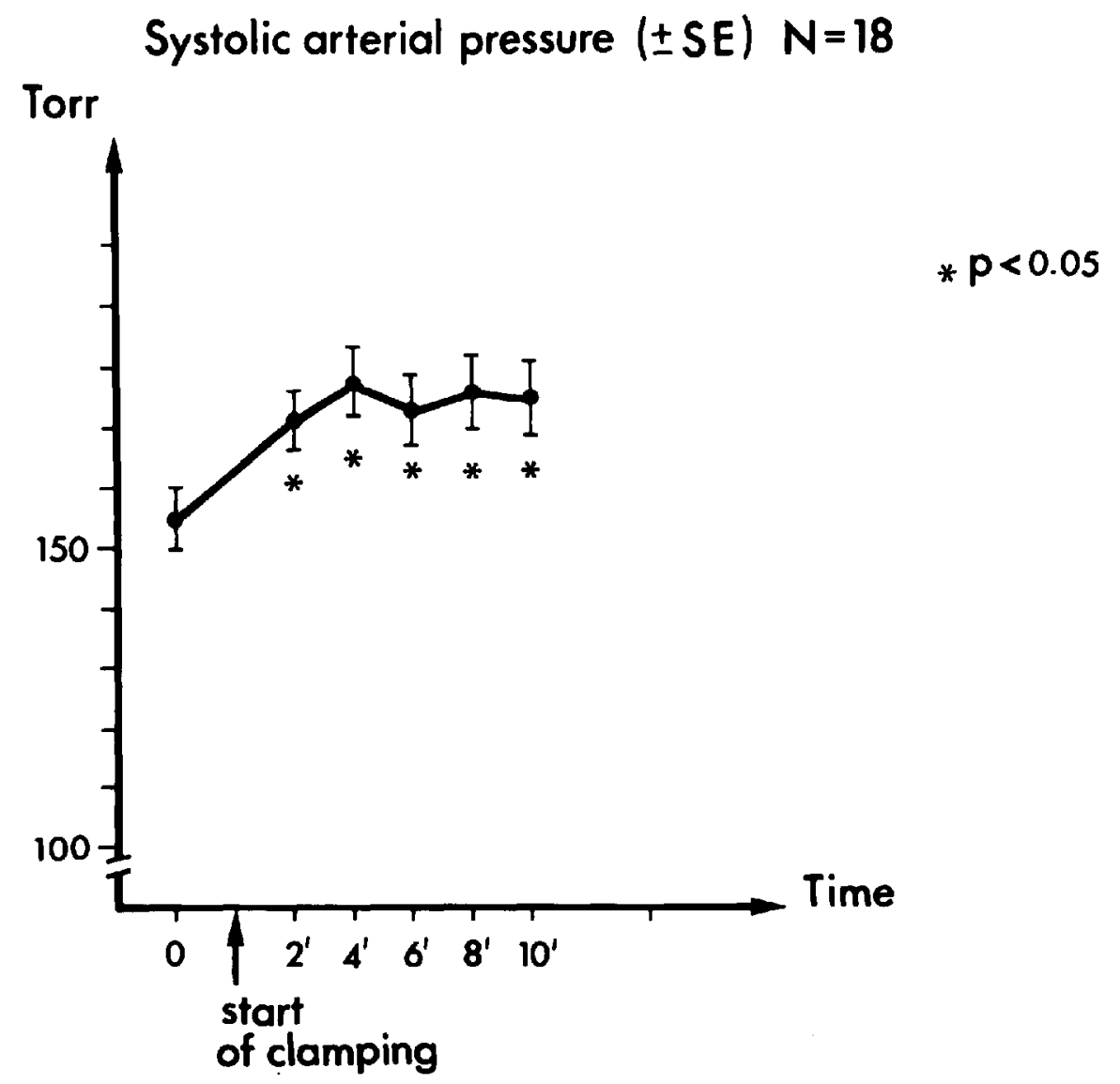

Ficure 3. The clamping of aorta increases systolic arterial pressure by 15 per cent.

a high level of circulating catecholamines the heart can maintain a constant stroke volume against an increased afterload, without any change in end-diastolic pressure. On the other hand, a diseased myocardium with left ventricular enddiastolic pressure above 12 torr would not show this inotropic response and an increase in afterload would precipitate acute failure. Though the precise mechanism controlling this homeometric autoregulation is not known, Sarnoff proposed local modification of norepinephrine or facilitation of its use by the myocardium. ${ }^{12}$

This Anrep reflex has its importance. It implies that the ventricle can maintain a constant stroke volume against a range of resistances without an increase in enddiastolic pressure. Furthermore, the increase in the rate of rise of ventricular pressure will shorten the systolic time. This Bowditch effect forestalls the reduction in diastolic interval with increasing heart rate. Thus a complete ventricular relaxation is attained before the next systole and the increase in end-diastolic volume is prevented. If we remember that coronary perfusion takes place during diastole, and that subendocardial perfusion is counteracted by the end-diastolic volume, this mechanism is not without clinical significance. 

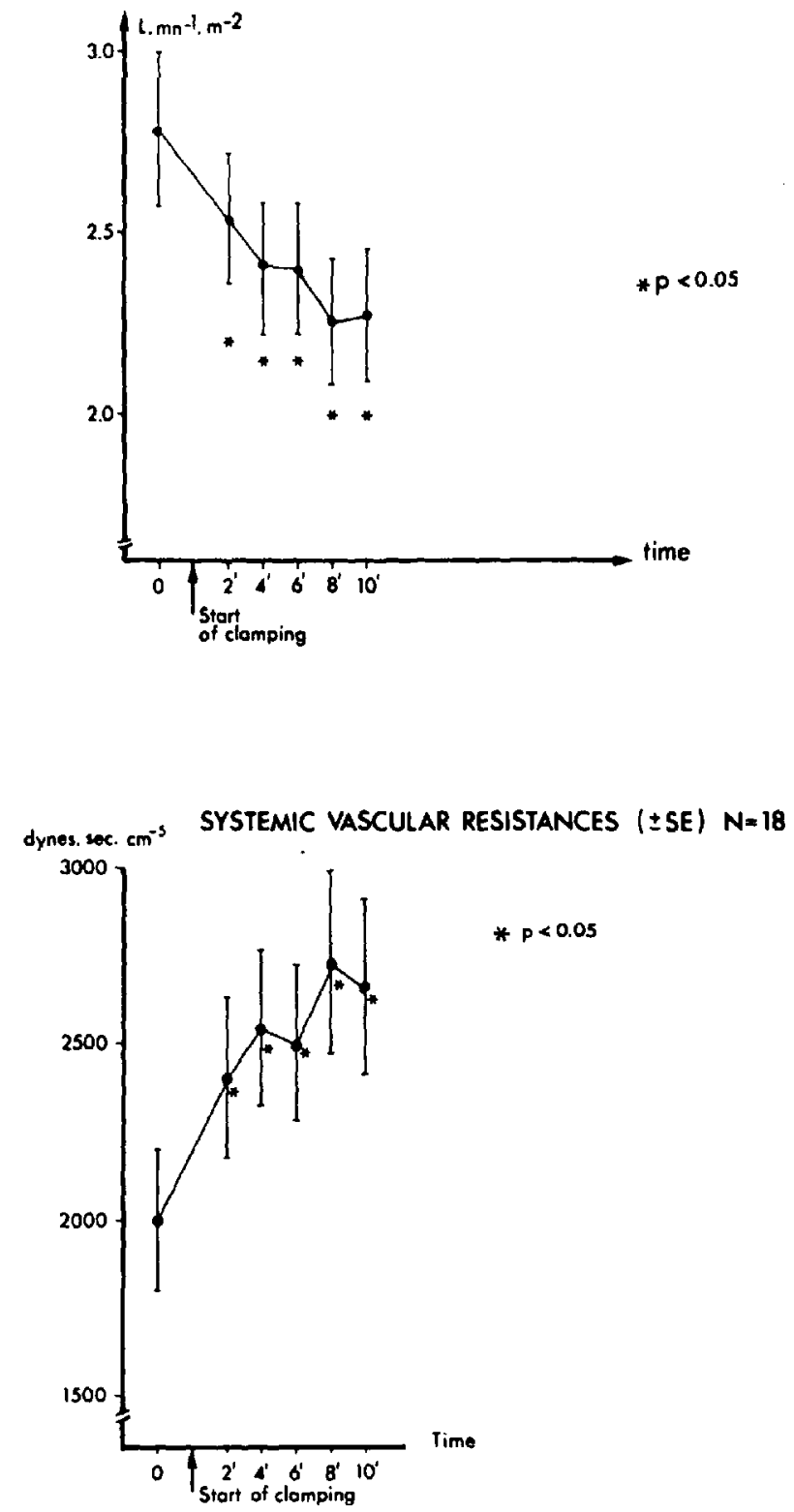

Ficune 4. The clamping of aorta induces a rapid and sustained increase in systemic vascular resistance (lower graph) which is paralleled by a decrease in cardiac output (upper graph).

In our patients these mechanisms either were silent or ineffective because the response to the increased afterload was a reduction in stroke volume and no change in systolic work. It is known that anaesthesia, old age and hypertension are accompanied by modifications of the integrative mechanism of circulatory reflexes. An example is shown in Figure 6 which indicates the inadequacy of baroreceptor 


\section{SYSTOLIC INDEX $( \pm S E) \quad N=18$}

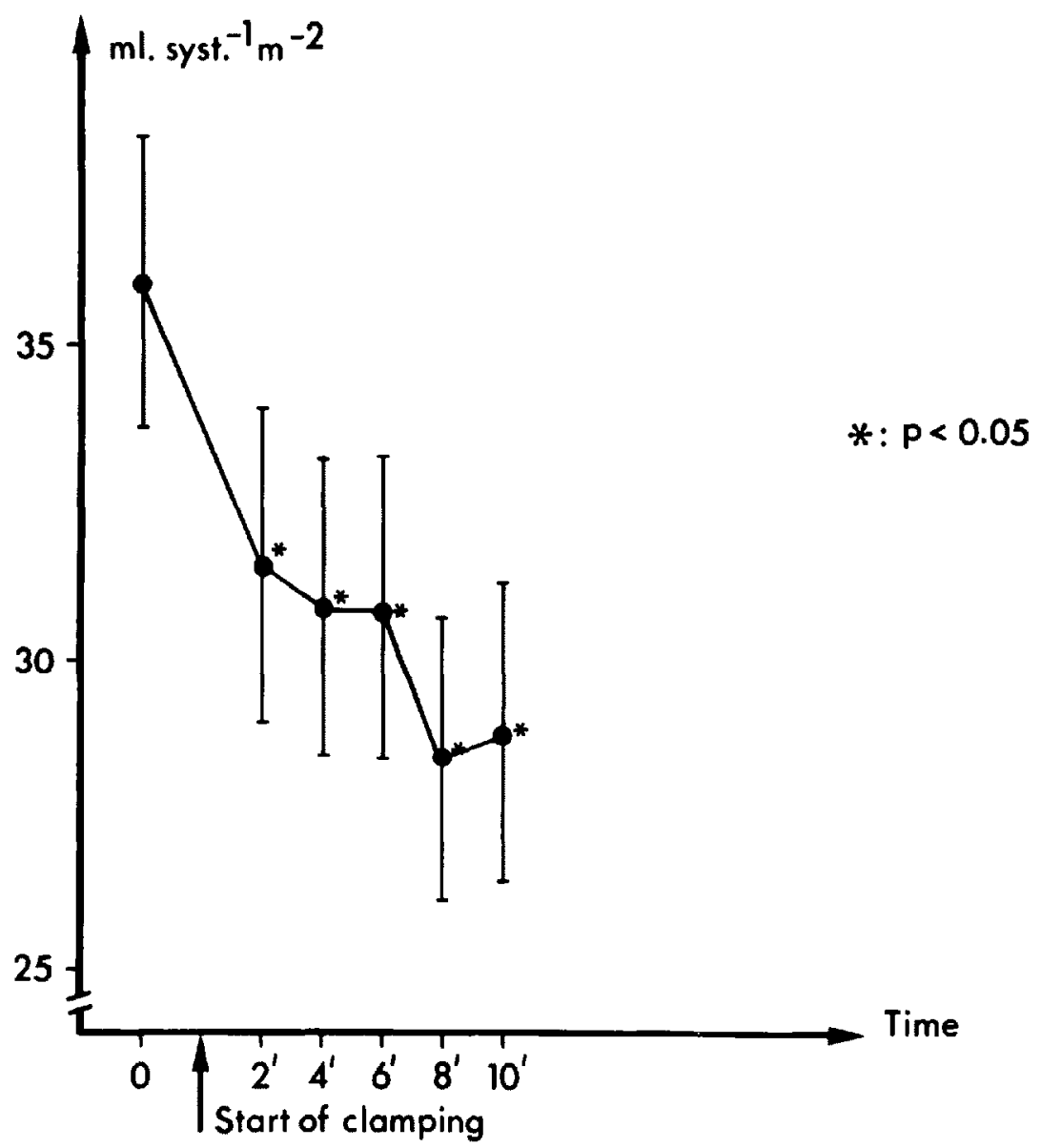

FIGURE 5. The decrease in cardiac output is due to a reduction in the stroke volume, for the heart rate does not change.

reflexes in our patients. Compared to the response of conscious patients of the same age group, it is obvious that under anaesthesia the reflex slowing of heart rate following an increase in systolic pressure is somewhat sluggish. The haemodynamic modification following aortic cross-clamping could be explained in part by inadequate circulatory reflexes either at the level of baroreceptors, integrative centres, afferent pathways, or effectors. There was neither homeometric autoregulation nor slowing of the heart rate in response to increased afterload.

This absence of homeometric autoregulation is not without interest. If we consider the low values of cardiac output after the first ten minutes of aortic occlusion, before blood loss interferes with the Starling mechanism, the situation can be cause for concern. While our patients had normal cardiac function, we are often required to cope with arteriosclerotic hearts or with hypertensive subjects with left ventricular hypertrophy. Their ventricular function curve is already depressed 


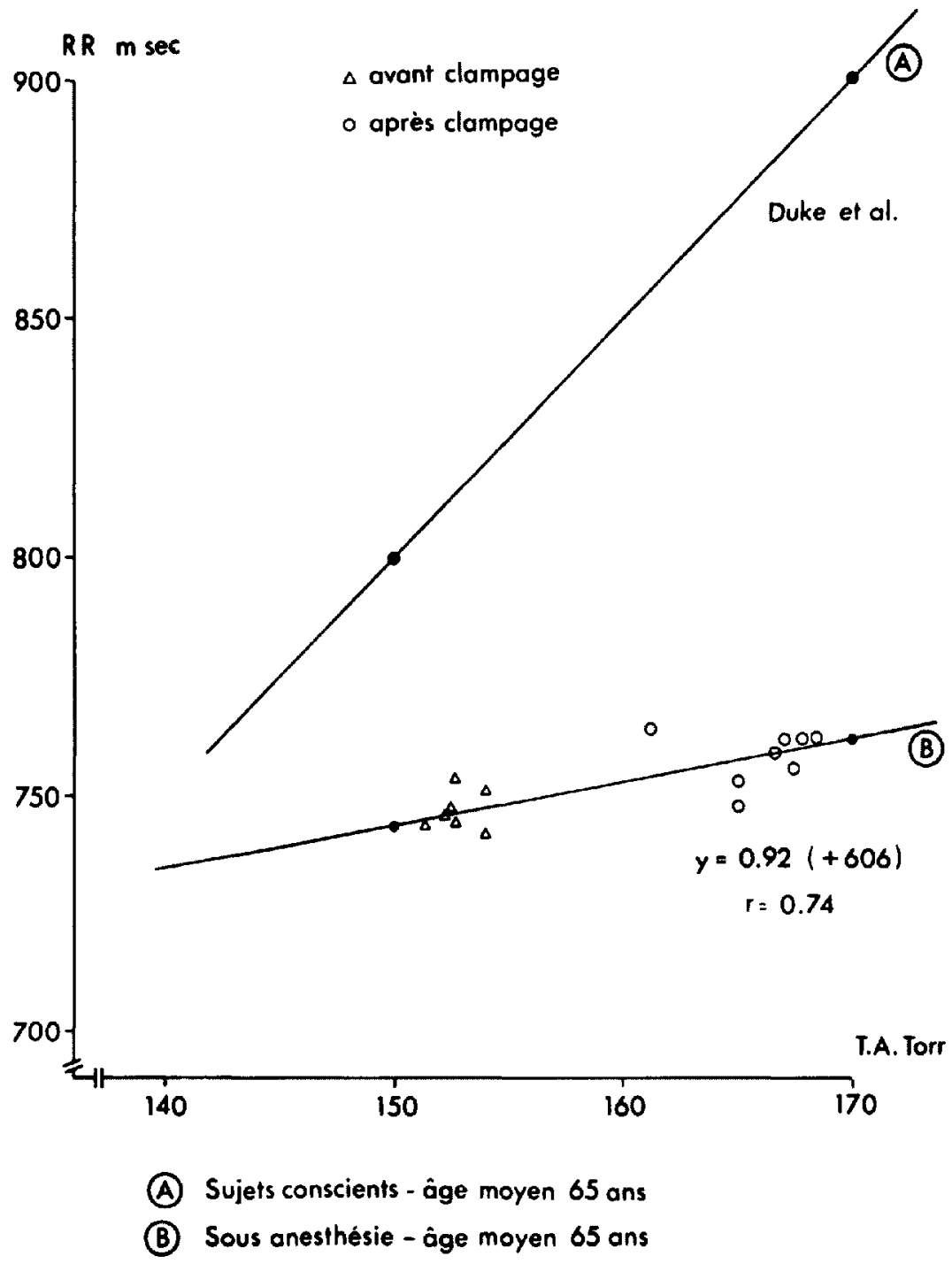

Ficune 6. The RR intervals (on the $y$ axis) in milliseconds, are augmented with increases in arterial pressure (on the $\mathrm{x}$ axis). The response of conscious subjects, adapted from Duke's data ${ }^{18}$ is shown on the upper regression line (A). In our anaesthetized patients, change in heart rate following the increase in blood pressure due to clamping of the aorta is almost non-existent (B). $(\Delta)$ represents systolic pressure before clamping and $(0)$ after clamping.

and a further increase in impedance could precipitate failure. We have stressed that, even before aortic clamping, the high systolic pressure and large pulse pressure indicate the higher velocity that the heart must impart to the blood to eject against an aorta that has lost its elasticity. The diastolic pump is no more effective in extending cardiac work to the diastolic period. The increased kinetic energy implies a much larger work, for it is proportional to the square of velocity. 
In our patients the systemic vascular resistance increased by nearly 40 per cent and the ventricle must generate a much higher pressure to maintain the same velocity.

We have seen that the necessary autoregulation and reflexes are not available and that cardiac performance decreases. It is obvious that anaesthesia must be conducted with great care. Hypertensive crisis and tachycardia must be particularly feared for they increase cardiac work while the time available for coronary perfusion is reduced. This can lead to cardiac failure due to subendocardial ischaemia. On the other hand, anaesthesia must spare sympathetic activity which presides over myocardial contractility and the homeometric autoregulation of the heart.

\section{SUMMARY}

Haemodynamic changes due to aortic cross-clamping were examined in 18 patients. It has been shown that the distal occlusion of the abdominal aorta induces an increased impedance to ejection. Because the mechanisms controlling the autoregulation of cardiac output and the circulatory reflexes are damped by anaesthesia, the augmentation of resistance is not followed by any increase in contractility or vasomotor tone and thus the cardiac output falls. Patients with chronic obstructive disease (Leriche) did not differ significantly from subjects with more acute obstruction (aneurysm), though the latter have a tendency to show more important changes in their haemodynamic response.

\section{RÉSUMÉ}

Nous avons étudié les changements hémodynamiques causés par locclusion de l'aorte abdominale chez 18 patients qui ne présentaient aucune évidence clinique de maladie cardiaque. L'étude a révélé que l'occlusion basse de l'aorte abdominale provoque une augmentation de l'impédance à l'éjection. Comme l'anesthésie amène une dépression des mécanismes d'autorégulation du débit cardiaque et des réflexes circulatoires, il n'y a pas d'amélioration de la contractilité myocardiaque ni du tonus vasomoteur, d'où baisse du débit cardiague. Les malades présentant une maladie obstructive progressive (Leriche) ne diffèrent pas de façon significative de ceux qui ont une obstruction subite (anévrysme); quoique ces derniers présentent des changements plus marqués. Une attention toute spéciale doit être portée à la stabilité de l'anesthésie afin d'éviter les crises hypertensives et de tachycardie, et de conserver une certaine activité sympathique.

\section{ACKNOWLEDGMENTS}

We are grateful to Drs. A. Joassin, N. Nadeau, R. Plante and F. Telmosse under whose care the patients were admitted. We wish to thank Dr. G. Fortin for helpful discussions during the preparation of this paper. 


\section{Abereviations}

$\mathrm{AP}=$ arterial pressure

$\overline{\mathrm{AP}}=$ mean arterial pressure

$\mathrm{CI}=$ cardiac index

$\mathrm{CO}=$ cardiac output

$\mathrm{HR}=$ heart rate

LVSWI = left ventricular stroke work index

$\overline{\mathrm{RAP}}=$ mean right atrial pressure

$\mathrm{SI}=$ stroke index

SVR = systemic vascular resistance

$\mathrm{SAP}=$ systolic arterial pressure

\section{REFERENCES}

1. Schneiweiss, R., Hadsall, F., \& Gordon, H. Earl. Prevention of hypotension following release of aortic occlusion. Surgery, vol. 60, no. 3, pp. 628-632 (September 1966).

2. Lim, R.C. Jh, Bergentz, S.E., \& Lewis, D.H. Metabolic and tissue blood flow changes resulting from nortic cross-clamping. Surgery, vol. 65, no. 2, pp. 304-310 (February 1969).

3. Vetto, R.M. \& Brant, B. Control of declamping shock. The American Journal of Surgery, vol. 116, pp. 273-279 (August 1968).

4. Brant, B., Armstrong, R.P., \& Vetto, R.M. Vasodepressor factor in declamp shock production. Surgery, vol. 67, no. 4, pp. 650-653 (April 1970).

5. Peray, M.O. The hemodynamics of temporary abdominal aortic occlusion. Annals of Surgery, vol. 168, no. 2, pp. 193-200 (August 1968).

6. Patterson, S.W., Piper, H., \& Starling, E.H. Regulation of the heart beat. J. Physiol. 48: 465 (1914).

7. ANREP, G.V. Lane medical lectures: studies in cardiovascular regulation. Stanford Univ. Publication 3: 205 (1936).

8. Starling, E.H. Linacre lecture on the law of the heart. Delivered at Cambridge, 1915, London, Longmans, Green \& Co. (1918).

9. Sarnoff, S.J., Mitchell, J.H., Gilmore, J.P., \& Remensnyder, J.P. Homeometric autoregualtion in the heart. Circulation research, vol. VII, pp. 1077-1091 (September 1960).

10. Rosenblueth, A., Alanis, J., Lopez, E., \& Rubio, R. Adaptation of ventricular muscle to different circulatory conditions. Arch. internat. Physiol. Biochem, 67: 358 (1959).

11. Taquini, A.C., Ferioso, J.D., \& Aramenda, P. Behavior of the right ventricle following acute constriction of the pulmonary artery.

12. Sarnoff, S.J., Brockman, S.K., Gilmone, J.P., Linden, R.J., \& Mrtchel., J.H. Regulation of ventricular contraction: influence of cardiac sympathetic and vagal nerve stimulation on atrial and ventricular dynamics. Circulation research 8: 1108 (1960).

13. Duke, P.C., WADE, J.G., HICKEY, R.F., \& LARSON, C.P. The effects of age on baroreceptor reflex function in man. Canad. Anaesth. Soc. J., vol. 23, no. 2, pp. 111-124 (March 1976). 